\title{
IMPLEMENTASI ALGORITMA MULTIFACTOR EVALUATION PROCESS (MFEP) UNTUK PENILAIAN TEKNISI PROMOSI KARYAWAN TETAP BERBASIS WEB
}

\author{
Bijak Ika Handhika dan Bonny Hendrawan \\ Universitas Budi Luhur Jakarta,Indonesia \\ Email: bijakika@gmail.com dan bonnyavolution@gmail.com
}

\begin{abstract}
The head of STO Muara Karang service area often has difficulty in assessing technicians and is often subjective so it is not necessarily the best criteria chosen to get promoted to be a permanent employee. Therefore, referring to the problem, the system is needed to facilitate the head of the service area in evaluating performance and can promote himself to join as a permanent employee. The research aims to assist the head of STO Muara Karang service area in making a decision on a permanent employee recommendation for technicians. The method used in this research is qualitative, and the application is built web-based using PHP programming language and database storage in MySQL. By utilizing the Multifactor Evaluation Process (MFEP) algorithm, decision making is done by giving intuitive and objective consideration to factors that are considered important. Based on the results of the test consideration is in the form of weighting system to take into account the assessment factors in technicians, the results of the assessment that has been done will directly produce data technicians who have competencies worthy to be promoted to a better career level. The results of this research with the application can help the leadership, in providing assessment and the results of the assessment produces objective decisions so that the leadership can recommend technicians according to the criteria.
\end{abstract}

Keyword: decision support system; assessment; multifactor evaluation process (MFEP).

Abstrak

Kepala area pelayanan STO Muara Karang seringkali mendapatkan kesulitan dalam memberikan penilaian terhadap teknisi dan seringkali bersifat subjektif sehingga belum tentu kriteria yang terbaik yang terpilih untuk mendapatkan promosi menjadi karyawan tetap. Oleh karena itu mengacu pada permasalahan tersebut dibutuhkan sistem untuk memudahkan kepala area pelayanan dalam mengevaluasi kinerja dan dapat mempromosikan dirinya untuk bergabung menjadi karyawan tetap. Adapun penelitian ini bertujuan untuk membantu kepala area pelayanan STO Muara Karang dalam membuat keputusan sebuah rekomendasi karyawan tetap untuk para teknisi. Metode yang digunakan dalam penelitian ini adalah kualitatif, serta aplikasi dibangun dengan berbasis web dengan menggunakan bahasa pemograman PHP dan penyimpanan database pada MySQL. Dengan memanfaatkan Algoritma Multifactor Evaluation Process (MFEP) yaitu pengambilan keputusan dilakukan dengan memberikan pertimbangan yang intuitif dan objektif terhadap faktor-faktor yang dianggap penting. Berdasarkan hasil pengujian Pertimbangan tersebut merupakan berupa pemberian bobot (weighting system) atas memperhitungkan faktor penilaian yang ada pada teknisi, hasil penilaian yang telah dilakukan akan langsung 
menghasilkan data teknisi yang memiliki kompetensi layak untuk di promosikan ke jenjang karir yang lebih baik. Hasil penelitian ini dengan adanya aplikasi dapat membantu pimpinan, dalam memberikan penilaian dan hasil penilaian tersebut menghasilkan keputusan yang objektif sehingga pimpinan dapat merekomendasikan teknisi dengan sesuai kriteria.

Kata kunci: sistem penunjang keputusan; penilaian; multifactor evaluation process (MFEP).

\section{Pendahuluan}

Perkembangan zaman yang semakin maju seperti sekarang ini membuat kebutuhan masyarakat semakin meningkat pula. Terlebih lagi didorong dengan adanya kemajuan ilmu pengetahuan dan teknologi yang sangat cepat (Cahya, 2014).

Kemajuan ilmu pengetahuan dan teknologi memiliki pengaruh yang sangat besar dalam berbagai bidang kehidupan manusia. Pendidikan sebagai salah satu bagian yang tidak terpisahkan dari proses pendewasaan manusia tentu di satu sisi memiliki andil yang besar bagi pengembangan ilmu pengetahuan dan teknologi tersebut, namun di sisi lain pendidikan juga perlu memanfaatkan kemajuan ilmu pengetahuan dan teknologi agar mampu mencapai tujuannya secara efektif dan efisien (Muhson, 2010).

Setelah perkembangan teknologi informasi yang demikian pesatnya, maka semakin banyaklah perusahaan di Indonesia menerapkan Sistem Informasi Manajemen (SIM) (Dewi Anggadini, 2013).

Dari penelitian terdahulu seperti yang dilakukan oleh Yudi Kristyawan dan Ahmad Rizeki pada tahun 2017, bahwa sistem pendukung keputusan merupakan sistem informasi interaktif yang menyediakan informasi, pemodelan, dan pemanipulasian data. Sistem itu digunakan untuk membantu pengambilan keputusan dalam situasi yang semiterstruktur dan situasi yang tidak terstruktur, dimana tak seorang pun tahu secara pasti bagaimana keputusan seharusnya dibuat (Sutrikanti, Situmorang, Fachrurrazi, Nurdiyanto, \& Mesran, 2018).

Menurut (Harumy \& Sulistianingsih, 2016) pemilihan keputusan dapat dilakuan dengan melalui pendekatan secara terstruktur terhadap suatu permasalahan dengan melalui proses penghimpunan data menjadi sebuah informasi serta menambahkan dengan komponen yang perlu di perhitungkan dalam pengambilan keputusan. Pengertian diatas menjelaskan bahwa sistem penunjang keputusan bukan sebagai alat pemilihan keputusan, namun merupakan sebuah sistem yang membantu memilih keputusan dengan melengkapi informasi dan data yang telah diolah secara relevan agar dapat memecahkan keputusan suatu masalah dengan cepat dan teliti. Sehingga sistem ini tidak dimaksudkan untuk menggantikan pada saat proses pembuatan keputusan. Menurut (Okaviana \& Susanto, 2014).

Metode Multifactor Evaluation Process merupakan metode kuantitatif dengan menggunakan sistem pembobotan (weighting system) yang ada pada sistem pengambilan keputusan multi faktor, keputusan diambil secara subjektif dengan memperhitungkan berbagai faktor atau kriteria yang memiliki pengaruh penting terhadap alternatif pilihannya. Keputusan tersebut berpengaruh secara strategis, lebih disarankan 
menggunakan sebuah pendekatan kuantitatif seperti multifactor evaluation process (MFEP) (Mustaqim, 2015).

PT. Telkom Divisi Access Network Site Operation (STO) Muara Karang yang merupakan kantor cabang pembantu divisi area Jakarta utara memiliki pelanggan indihome yang cukup banyak, dimana pada setiap jaringan memungkinkan akan terjadinya error. Maka dibutuhkan para teknisi yang handal dalam melakukan perbaikan gangguan dan dapat memenuhi target pasang baru ke pelanggan, dikarenakan adanya masalah tersebut maka penilaian terhadap teknisi diperlukan untuk menyaring teknisi yang handal dan professional untuk bergabung menjadi karyawan tetap.

(Ardana, Mujiati, \& Utama, 2012) menyatakan bahwa kepuasan kerja yang rendah dapat menimbulkan berbagai dampak negatif seperti disiplin kerja merosot, semangat dan gairah kerja menurun, dan sering melakukan kesalahan dalam pekerjaan sehingga berakibat pada produktivitas kerja yang menurun.

(Marisa, 2020) menyatakan bahwa Kinerja dapat ditingkatkan melalui peningkatan kepuasan kerja, karena kepuasan kerja memberikan semangat kepada karyawan.

Menurut (Handoko, 2014) penilaian kinerja karyawan perlu dilakukan pada setiap perusahaan untuk mengetahui prestasi para karyawannya, sebagai cara untuk mengetahui prestasi yang telah di peroleh oleh setiap karyawan apakah prestasinya merupakan kategori baik, cukup atau kurang. Tahap penilaian teknisi untuk menjadi karyawan tetap pada PT. Telkom mempunyai tahapan dan penilaian teknis dimana dapat mempromosikan teknisi tersebut untuk menjadi karyawan tetap. Penilaian tersebut mempunyai beberapa point penilaian yaitu orientasi pelayanan, integritas, komitmen, disiplin, dan kerjasama dari para teknisi. Kepala area pelayanan STO Muara Karang seringkali mendapatkan kesulitan dalam memberikan penilaian terhadap teknisi dan seringkali bersifat subjektif sehingga belum tentu kriteria yang terbaik yang terpilih untuk mendapatkan promosi menjadi karyawan tetap. Jika salah dalam melakukan penilaian untuk promosi karyawan tetap, hal ini akan berdampak pada menurunnya kinerja teknisi dalam menyelesaikan pekerjaan.

Mengacu pada permasalahan tersebut, peneliti tertarik untuk membangun suatu sistem pendukung keputusan penilaian teknisi yang dapat membantu kepala area pelayanan STO Muara Karang dalam membuat sebuah rekomendasi karyawan tetap untuk para teknisi. Dengan memperhitungkan faktor penilaian yang ada pada teknisi untuk promosi menjadi karyawan tetap melalui Multifactor Evaluation Process. Kemudian diharapkan nantinya sistem penilaian ini akan membantu kepala area pelayanan STO Muara Karang dalam penilaian dan rekomendasi promosi karyawan tetap kepada teknisi

\section{Sistem Pendukung Keputusan}

Sistem Pendukung Keputusan pada dasarnya adalah sebuah sistem yang dapat memberikan sebuah keputusan dan memiliki kemampuan dalam memecahkan masalah yang terstruktur maupun yang tidak terstruktur. Dengan menggunakan sistem ini dapat membantu dalam pengambilan keputusan dalam situasi yang tidak sistematis, dimana pada saat itu tak seorangpun tahu secara pasti dalam menentukan keputusan yang seharusnya dibuat (Diwanda, Isnawaty, \& La Ode Hasnuddin, 2016). 
Sistem pendukung keputusan merupakan pengembangan dari suatu sistem informasi manajemen terkomputerisasi yang dibuat sedimikian rupa sehingga bersifat interaktif dengan kepada penggunanya (Afriyanli \& Sabandi, 2020).

\section{Multifactor Evaluation Process (MFEP)}

Pada metode multifactor evaluation process (MFEP) langkah pertama seluruh kriteria yang menjadi faktor penting dalam melakukan suatu pertimbangan pada saat diberikan pembobotan (weighting) yang sesuai. Pada langkah yang sama dilakukan juga terhadap alternatif-alternatif yang akan dipilih yang kemudian dapat di simpulkan berkaitan dengan faktor-faktor pertimbangan tersebut. Bahwa metode MFEP menentukan alternatif dengan nilai tertinggi adalah solusi yang terbaik berdasarkan kriteria yang telah dipilih sebelumnya (Harumy \& Sulistianingsih, 2016).

Menurut (Render;, Stair; \& Pratiwi, H., 2014) Multi Factor Evaluation Process (MFEP) metode pengambilan keputusan yang tepat ketika seorang individu, kelompok, atau organisasi menghadapi sejumlah faktor dalam pengambilan keputusan. Dengan MFEP, pembuat keputusan memberikan weighting system dari setiap faktor. Bobot berkisar dari 0 sampai 1 . Kemudian, untuk setiap alternatif, semua faktor dievaluasi.

\section{Komponen Sistem Pendukung Keputusan}

Menurut Muhammad (Dahria \& Ishak, 2014), pada suatu sistem pendukung keputusan (SPK) memiliki tiga komponen subsistem yang utama untuk menentukan kapabilitas teknis sistem pendukung keputusan yaitu subsistem pengelolaan data (database), subsistem pengelolaan model (modelbase) dan subsistem pengelolaan dialog (userinterface).

\section{Metode Penelitian}

Menurut (Sugiyono, 2017), metode penelitian kualitatif adalah metode penelitian yang berlandaskan pada filsafat postpositivisme digunakan atau interpretif, digunakan untuk meneliti pada kondisi objek yang alamiah, dimana peneliti adalah sebagai instrument kunci. Selain itu, metode ini juga memberikan informasi mengenai sisi lain dari responden yang sering bertentangan dari sisi perilaku, opini, emosi, dan hubungan individual. Penelitian ini dilakukan dengan beberapa langkah dari mulai pengumpulan data, analisis hingga hasil. Hal ini dilakukan agar tercapai suatu tujuan penelitian yang diharapkan. Adapun metodologi penelitian yang dilakukan adalah:

1. Studi Literatur yaitu dengan membaca jurnal-jurnal yang terkait dengan penelitian mengenai sistem penunjang keputusan, dan algoritma Multi Factor Evaluation Process (MFEP). Selain dari jurnal, studi literatur juga dilakukan melalui buku teks sistem penunjang keputusan, dan algoritma Multi Factor Evaluation Process.

2. Melakukan observasi penelitian langsung pada telkom sto muara karang mengenai kegiatan teknisi untuk mendapatkan data atau informasi yang diperlukan.

3. Melakukan wawancara secara mendalam kepada para teknisi. Selain itu, metode ini juga memberikan informasi mengenai sisi lain dari responden yang sering bertentangan dari sisi perilaku, opini, emosi, dan hubungan individual. 


\section{Hasil dan Pembahasan}

\section{A. Tampilan Layar}

\section{Tampilan layar login}

Berikut ini adalah tampilan layar login. Dimana sebelum user masuk ke menu utama terlebih dahulu diwajibkan untuk melakukan login.

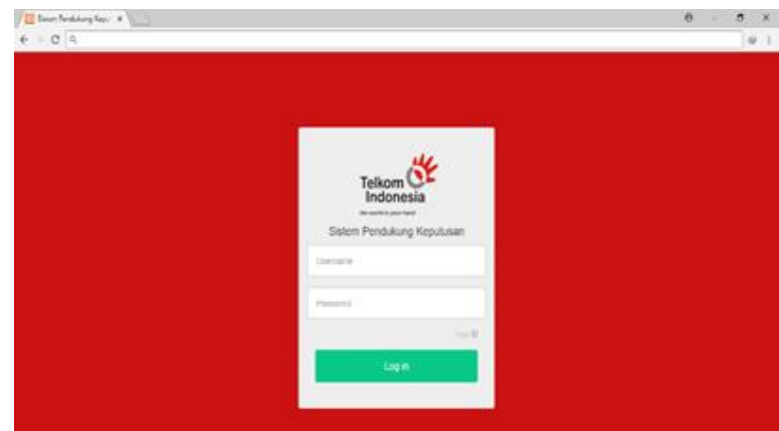

Gambar 1. Tampilan layer login

\section{Tampilan layar menu utama}

Berikut ini adalah tampilan layar menu utama. Dimana setelah berhasil melakukan login maka akan tampil halaman menu-menu yang admin dapat akses untuk mengolah data mengenai pegawai.

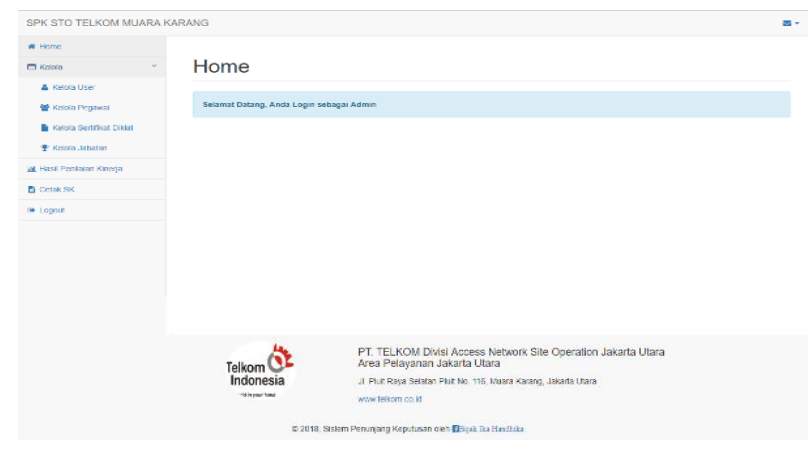

Gambar 2. Tampilan layer menu utama

\section{Tampilan layar menu master kriteria}

Berikut ini adalah tampilan layar menu master kriteria. Dimana supervisor dapat membuat sebuah kriteria penilaian sebagai acuan untuk penialaian pegawai dan memiliki bobot yang dapat di perhitungkan.

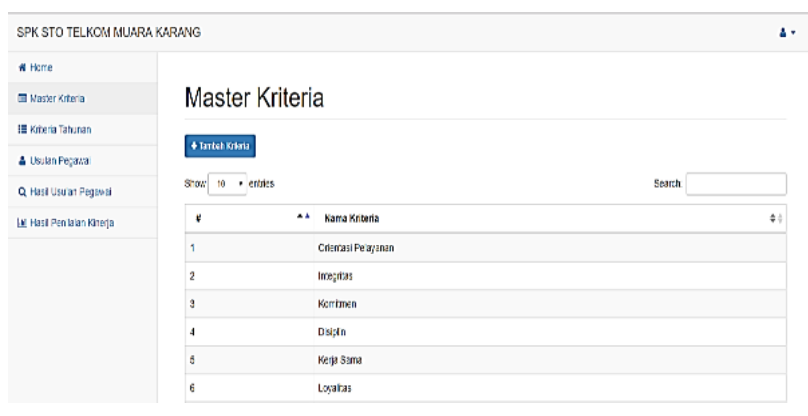

Gambar 3 Tampilan Layar Menu Master Kriteria 


\section{Tampilan Layar menu penilaian kinerja}

Berikut ini adalah tampilan layar menu penilaian kinerja. Dimana asman dapat melakukan penilaian kinerja terhadap pegawai yang akan mendapatkan nilai sebagai promosi jabatan.

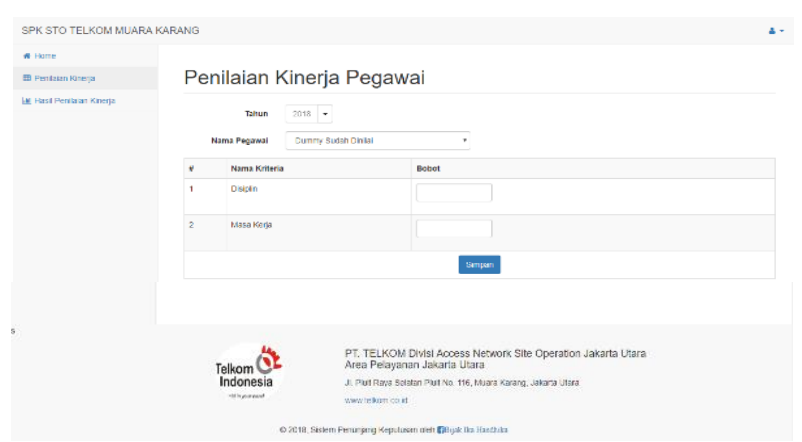

Gambar 4. Tampilan layer menu penilaian kinerja

\section{Tampilan layar menu hasil penilaian}

Berikut ini adalah tampilan layar menu master hasil penilaian. Dimana dimana asman dapat melihat presentase penilaian pegawai yang telah dilakukan penilaian.

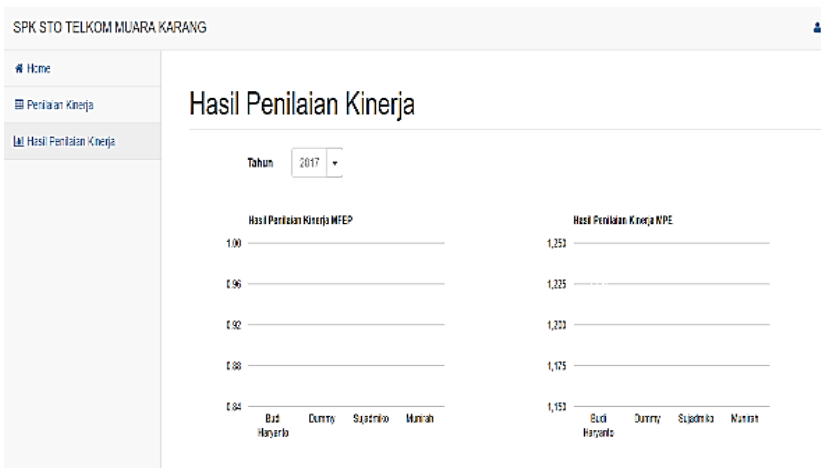

Gambar 5. Tampilan layar menu hasil penilaian

\section{B. Hasil uji coba program}

Untuk mengetahui apakah aplikasi ini dapat menentukan rekomendasi pemilihan karyawan tetap, maka akan dilakukan uji coba terhadap aplikasi ini. Uji coba yang akan dilakukan adalah dengan menguji perhitungan nilai yang di peroleh karyawan.

\section{Hasil uji coba rekomendasi}

Proses uji coba penentuan rekomendasi terhadap anggota yang dilakukan penilaian untuk mendapatkan promosi jabatan.

Tabel 1

Tabel Perhitungan Rekomendasi

\begin{tabular}{cccccc}
\hline $\begin{array}{c}\text { Nomor } \\
\text { Kriteria }\end{array}$ & $\begin{array}{c}\text { NIP } \\
\mathbf{7 0 2 1 0 9}\end{array}$ & $\begin{array}{c}\text { NIP } \\
\mathbf{8 0 1 2 0 4}\end{array}$ & $\begin{array}{c}\mathbf{7 2 0 4 0 6} \\
\mathbf{7 2 0 4}\end{array}$ & $\begin{array}{c}\mathbf{8 9 0 5 1 1} \\
\text { IIP }\end{array}$ & $\mathbf{9 0 1 1 0 3}$ \\
\hline 001 & 2 & 2 & 1,6 & 1,6 & 1,4 \\
\hline 002 & 3 & 1,5 & 2,4 & 2,1 & 2,4 \\
\hline 003 & 1,2 & 1,6 & 1,2 & 1,6 & 0,8 \\
\hline 004 & 1,2 & 1,2 & 0,9 & 1,2 & 1,2 \\
\hline
\end{tabular}




\begin{tabular}{cccccc}
\hline 005 & 0,6 & 0,8 & 0,6 & 1 & 0,4 \\
\hline 006 & 0,4 & 0,5 & 0,4 & 0,4 & 0,4 \\
\hline Total & 8,4 & 7,6 & 7,1 & 7,9 & 6,6 \\
\hline Rank & 1 & 3 & 4 & 2 & 5 \\
\hline
\end{tabular}

Dari tabel diatas terlihat bahwa bobot evaluasi adalah 8,4 merupakan bobot tertinggi dan mendaptkan promosi jabatan.

\section{Hasil Uji Coba Perhitungan}

Hasil uji coba terlihat pada tabel 11 Dari hasil perhitungan ranking diatas dapat dilihat alternatif dengan nip 702109 atas nama Budi Haryanto mendapat nilai terbesar yaitu 8,4 sehingga menjadi rank 1 atau alternatif terbaik yang berarti Budi Haryanto dapat terpilih sebagai promosi karyawan tetap sto muara karang.

Tabel 2

Tabel Perhitungan Rekomendasi

\begin{tabular}{ccccc}
\hline $\begin{array}{c}\text { Nomor } \\
\text { Kriteria }\end{array}$ & $\begin{array}{c}\text { Bobot } \\
\text { Faktor }\end{array}$ & $\begin{array}{c}\text { Evaluasi } \\
\text { Faktor }\end{array}$ & $\begin{array}{c}\text { Bobot } \\
\text { Evaluasi }\end{array}$ \\
\hline 001 & 0,2 & $\mathrm{x}$ & 10 & 2 \\
\hline 002 & 0,3 & $\mathrm{x}$ & 10 & 3 \\
\hline 003 & 0,2 & $\mathrm{x}$ & 6 & 1,2 \\
\hline 004 & 0,15 & $\mathrm{x}$ & 8 & 1,2 \\
\hline 005 & 0,1 & $\mathrm{x}$ & 6 & 0,6 \\
\hline 006 & 0,05 & $\mathrm{x}$ & 8 & 0,4 \\
\hline Total & 1 & & & 8,4 \\
\hline
\end{tabular}

Dari tabel diatas terlihat bahwa bobot evaluasi adalah 8,4 merupakan bobot tertinggi dan mendaptkan promosi jabatan.

\section{Kesimpulan}

Berdasarkan perancangan, pembuatan, serangkaian uji coba dan analisa program dari aplikasi sistem penunjang keputusan penilaian teknisi, maka dapat diambil suatu kesimpulan antara lain. Dengan adanya aplikasi sistem pendukung keputusan penilaian teknisi menggunakan Algoritma Multifactor Evalution Process (MFEP) maka Pimpinan dapat memutuskan siapa Anggota yang benar-benar sesuai dengan kriteria perusahaan.

Penelitian ini menghasilkan sistem pendukung keputusan yang membantu manajer dalam mempromosikan pegawai secara objektif. Aplikasi ini menghasilkan sistem pendukung keputusan yang menyajikan hasil nilai pegawai berupa grafik dengan menggunakan metode Multifactor Evalution Process (MFEP). Memudahkan pimpinan STO Muara Karang dalam melakukan penilaian terhadap teknisi dan dapat mengusulkan promosi karyawan dengan objektif. 


\section{BIBLIOGRAFI}

Afriyanli, Hana Khairi, \& Sabandi, Ahmad. (2020). Pengaruh Supervisi Kepala Sekolah Terhadap Kinerja Guru. JMKSP (Jurnal Manajemen, Kepemimpinan, Dan Supervisi Pendidikan), 5(1), 51.

Ardana, I. Komang, Mujiati, Ni Wayan, \& Utama, I. Wayan Mudiartha. (2012). Manajemen sumber daya manusia. Yogyakarta: Graha Ilmu.

Cahya, Andika. (2014). Sistem aplikasi pembelian smartphone menggunakan metode topsis analisis berbasis android. University of Muhammadiyah Malang.

Dahria, Muhammad, \& Ishak, F. Y. (2014). Pendukung keputusan seleksi calon polri baru di Polda Kota Medan menggunakan metode Multi Factor Evaluation Process (MFEP). Jurnal Saintikom, 13(2), 83-94.

Dewi Anggadini, Sri. (2013). Analisis sistem informasi manajemen berbasis komputer dalam proses pengambilan keputusan. Majalah Ilmiah Unikom.

Diwanda, Subhan Akbar, Isnawaty, Isnawaty, \& La Ode Hasnuddin, S. Sagala. (2016). Sistem pendukung keputusan penilaian kinerja karwayan menggunakan metode Multifactor Evaluation Process pada Pt. Konsuil Wilayah Sulawesi Tenggara. SemanTIK, 2(1).

Handoko, T. Hani. (2014). Manajemen Personalia dan Sumber Daya Manusia. Yogyakarta: BPFE.

Harumy, T. Henny Febriana, \& Sulistianingsih, Indri. (2016). Sistem penunjang keputusan penentuan jabatan manager menggunakan metode MFEP pada Cv. Sapo Durin. Semnasteknomedia Online, 4(1), 3.

Marisa, Marisa. (2020). Pengaruh kompensasi, kepuasan kerja dan motivasi kerja terhadap kinerja karyawan pada PT. Bank Syariah Mandiri Cabang Palembang Simpang Patal. Adl Islamic Economic: Jurnal Kajian Ekonomi Islam, 1(1), 1-12.

Muhson, Ali. (2010). Pengembangan media pembelajaran berbasis teknologi informasi. Jurnal Pendidikan Akuntansi Indonesia, 8(2).

Mustaqim, Abdul. (2015). Abdul. Metodologi Penelitian al-Qur" an dan Tafsir. Yogyakarta: Idea Press Yogyakarta.

Okaviana, Muhamad Reza, \& Susanto, Rani. (2014). Sistem pendukung keputusan rekomendasi pemilihan program studi menggunakan metode Multifactor Evaluation Process di SMA Negeri 1 Bandung. Jurnal Ilmiah Komputer dan Informatika (Komputa), 3(2), 2014.

Render;, Stair; \& Pratiwi, H. (2014). Berprestasi menggunakan Metode multifactor. sistem informasi, 5(2), 95-101.

Sugiyono, P. D. (2017). Metode Penelitian Bisnis: Pendekatan Kuantitatif, Kualitatif, 
Kombinasi, dan R\&D. Penerbit CV. Alfabeta: Bandung.

Sutrikanti, Nidia, Situmorang, Hotmelinsa, Fachrurrazi, Fachrurrazi, Nurdiyanto, Heri, \& Mesran, Mesran. (2018). Implementasi pendukung keputusan dalam pemilihan calon peserta cerdas cermat tingkat SMA menerapkan metode Vikor. Jurikom (Jurnal Riset Komputer), 5(2), 109-113. 